\title{
Gantzer's Muscle-like Variation Inserted into the Forearm Flexor Retinaculum
}

\begin{abstract}
By
Masahiko KIDA and Hajime ISHIDA*

Department of Anatomy, St. Marianna University School of Medicine, Kawasaki, 213 Japan.

*Department of Anatomy, Sapporo Medical College, Sapporo, 060 Japan.

- Received for Publication, November 22, 1988-

Key words: Forearm flexor muscles, Muscle variation, Gantzer's muscle, Median nerve, Nerve fiber analysis.

Summary: A rare muscle variation belonging to the forearm flexor muscle group has been observed in three forearms out of nearly 200 Japanese cadavers. It arose from the well developed fascia of the superficial forearm flexor group, crossed the median nerve obliquely and posteriorly lying radial to that nerve, and was inserted into the flexor retinaculum. The muscle variations in the three cases were discussed according to the concept of "corrected" nerve-muscle specificity and conservative morphology. They were conclusively ascribable to the original antebrachial flexor group of Yamada. This seemed to indicate that the variations were related or identical to Gantzer's muscle, and that they showed a possible original or archaic pattern of the original antebrachial flexors.
\end{abstract}

In comparative anatomy, homogeny and phylogeny of the forearm flexor muscles are of considerable interest. However, a clear and valid elucidation of this subject was not made until recently in spite of much discussion, such as the works of Eisler (1895), Gräfenberg (1906), Haines (1950), Howell (1936), Lewis (1902), McMurrich (1902), Ribbing (1938) and Straus (1942). Yamada (1986) has given a highly reliable interpretation to the theme based on the findings of innervation as seen in the stable branching pattern of muscular branches from the median nerve observed after ensheathing the epineurium, namely nerve fiber analysis.

The present authors have encountered three cases of a rare forearm flexor muscle variation arising from the flexor digitorum superficialis (FDS), and crossing the median nerve posteriorly to be inserted into the proximal margin of the flexor retinaculum. These variations were considered to be not only rare but also very interesting in connection with the homogeny and phylogeny of the FDS. The authors tried to grasp the morphological significance of these variations according to both the conservative morphological method and the nerve fiber analysis method employed by Yamada, which seems to give stable and reliable findings and to provide a systematic interpretation in the field of comparative myology.

\section{Findings}

The muscle variations in question were observed in three forearms out of nearly 200 Japanese cadavers at Sapporo Medical College in 1987, Niigata University in 1982 and St. Marianna University in 1988. The muscular branch of nerve to the muscle variation in the 
first case was clarified by means of reconstruction with a binocular microscope though the muscular branches from the median nerve were partially damaged. The innervation in the latter two cases could not be found at all.

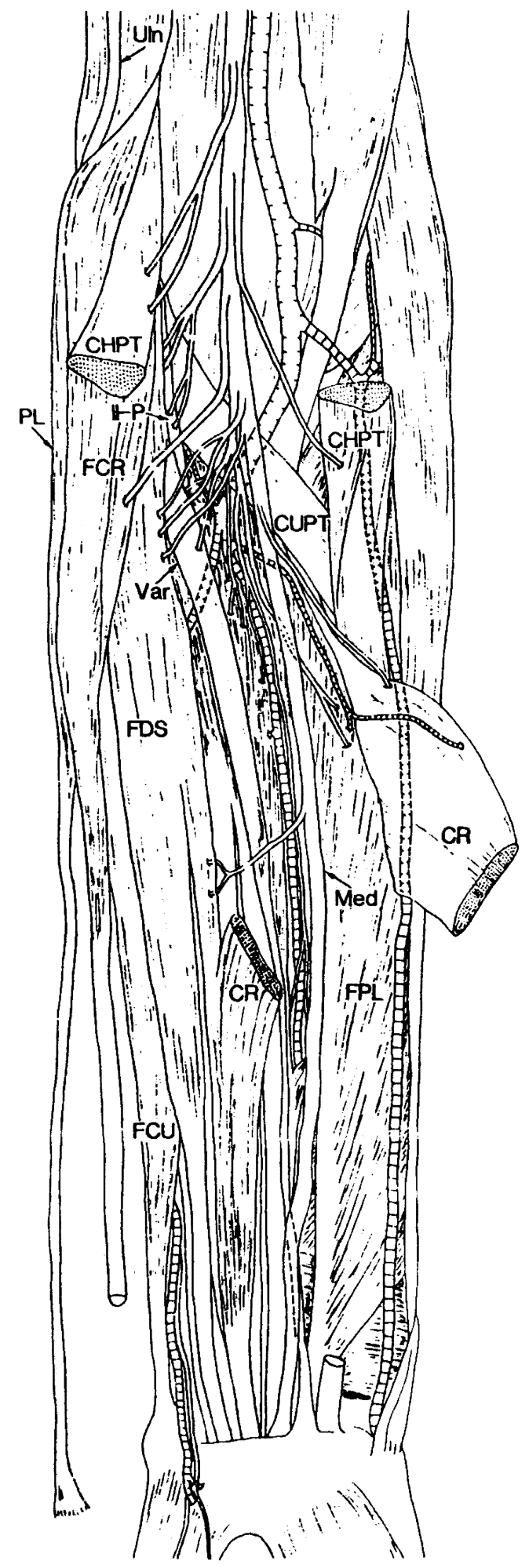

Fig. 1. Anterior view of the left forearm flexors and related nerves in the first case.

\section{Case 1.}

The muscle of variation in the left forearm of a male cadaver (Fig. 1 \& Plate 1) arose from the ulnar and distal portion of the well developed longitudinal fascia (referred to as connecting fascia by Kida, 1988) which was observable on the deep surface of the superficial forearm flexor group and was made up of the two intermuscular septa, one of which was located between the pronator teres and the flexor carpi radialis (radial septum: RS), and the other between the latter and the flexor digitorum superficialis (ulnar septum: US in Fig. 2). The spindle-like muscle belly was $110 \mathrm{~mm}$ long and $8 \mathrm{~mm}$ in maximum breadth. The muscle with a slim tendon was $210 \mathrm{~mm}$ in whole length. It became a slim tendon after obliquely crossing the median nerve posteriorly to lie radial to the nerve. The tendon ran downward and forward along the radial side of the nerve, and was finally attached to the proximal margin of the flexor retinaculum on the ulnar side of the flexor carpi radialis. The muscular branches of the median nerve after reconstruction are also shown in Fig. 1 (damaged branches are indicated by gaps). The apparent branching pattern of the median nerve before nerve fiber

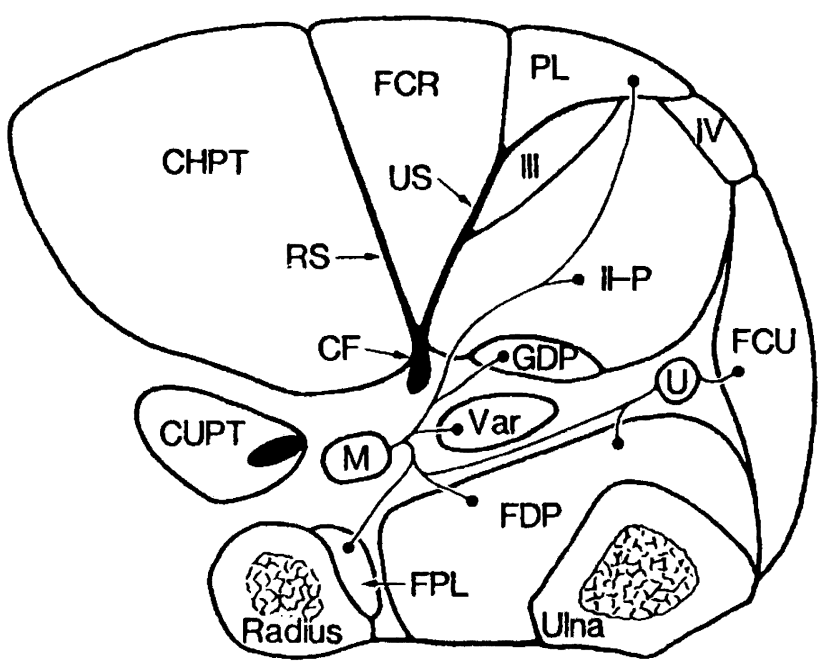

Fig. 2. Schematic diagram, showing the relation between the forearm flexor muscles and their muscular branches of nerve in cross-section. 
analysis differed from the pattern obtained after fiber analysis (to ensheath the epineurium) (Fig. 3-B). The intramuscular nerve distribution (Fig. 4) demonstrated that all the twigs concerning this muscle variation, with the exception of one twig, made a unique network which supplied the muscle with the mixed nerve fibers. The exceptional twig seemed to be associated with only proprioception, judging from the finding that its terminal organs were tendon spindles and a sort of Pacinian lamellated corpuscles. Therefore this muscle variation was thought to be phylogenetically a homogenous muscle.

\section{Case 2.}

The origin, course and insertion of the

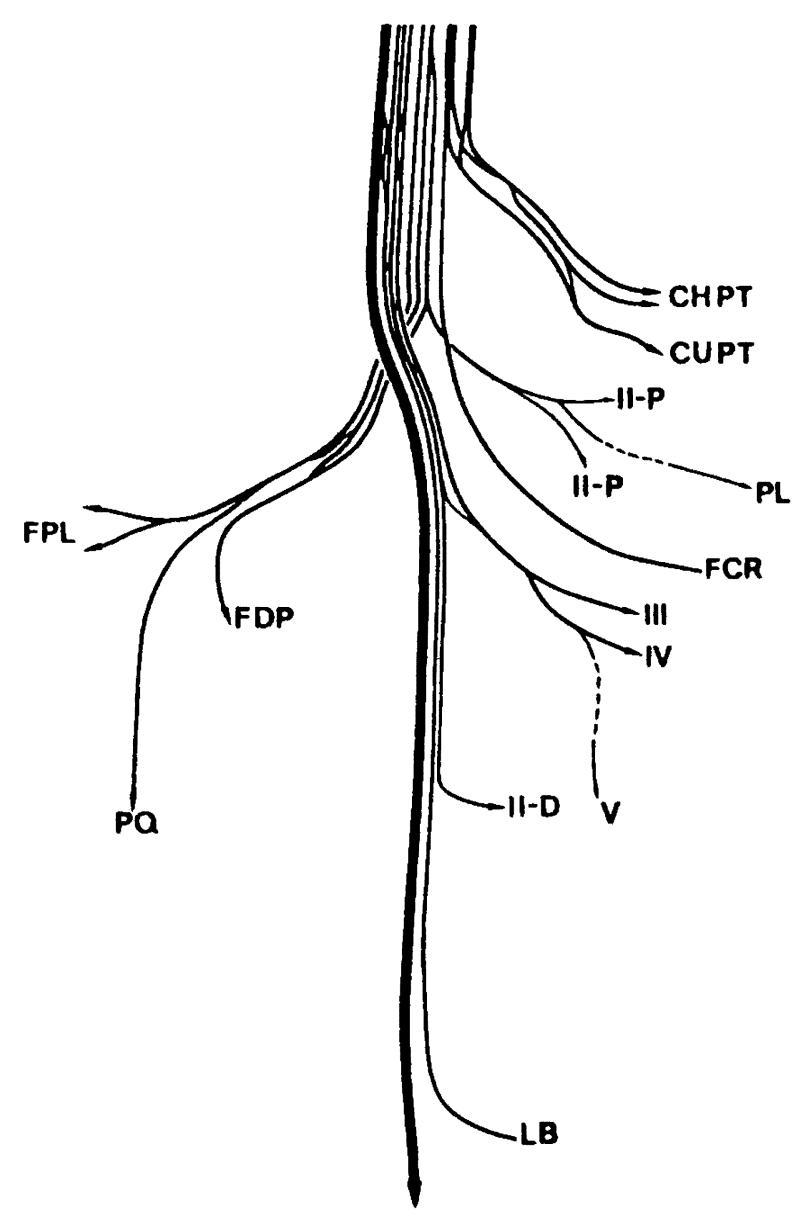

A muscle variation in the left forearm of a male cadaver was the same as those of the first case (Fig. 5). The insertion was, however, in some degree different from that in the first case. The distal part of the tendon of insertion ran downward along the radial side of the median nerve. It gradually again crossed the median nerve anteriorly to lie ulnar to the nerve above the wrist, finally being inserted into the proximal margin of the flexor retinaculum. Another muscular bundle arose from the more proximal portion of the well developed fascia (CF) than the origin of the preceding variation from the same fascia and was attached to the tendon of the flexor digitorum profundus (FDP) for the index finger by a fine tendon. Such a muscular bundle can be called Gantzer's muscle (M. accessorius ad flexorem pro-

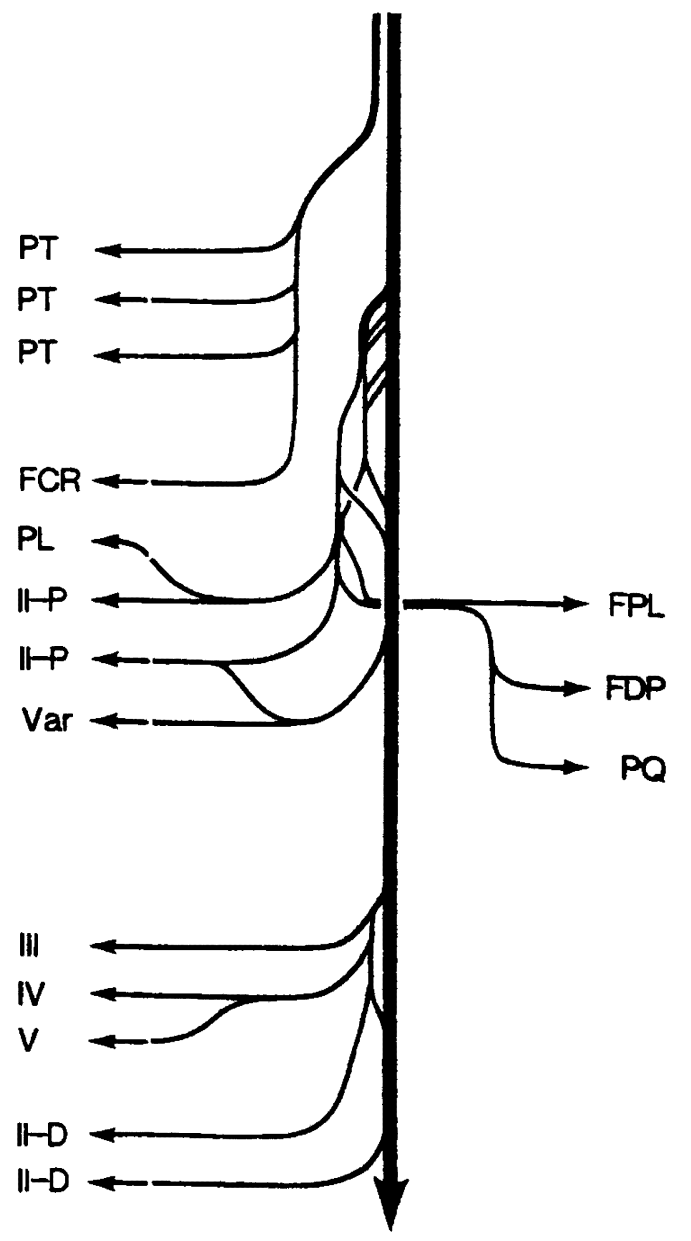

B

Fig. 3. Diagrams, showing branching of the median nerve.

A. The common pattern (Yamada, 1986).

$\mathrm{B}$; The pattern in the first case. 

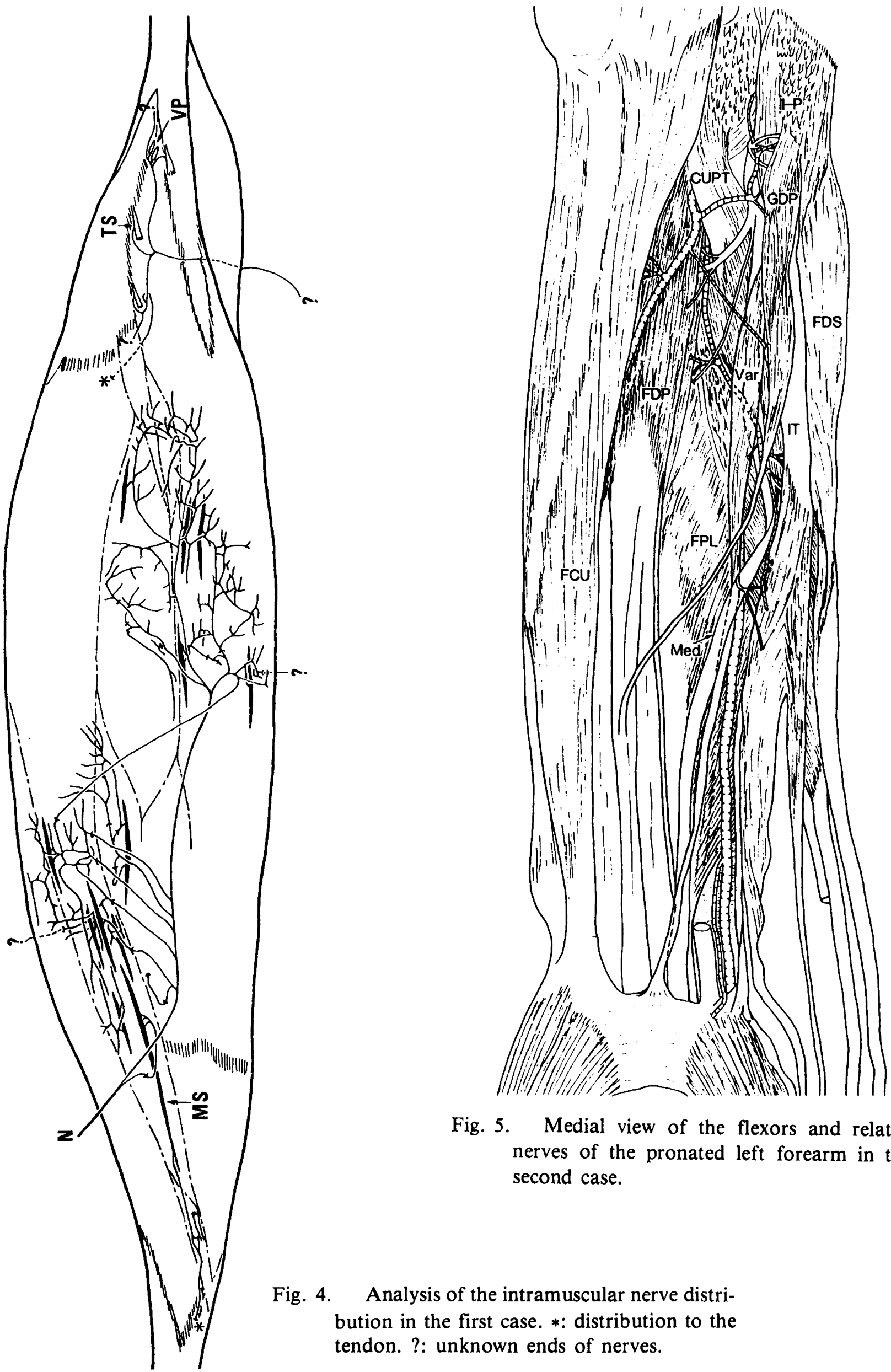

Fig. 5. Medial view of the flexors and related nerves of the pronated left forearm in the second case.

Fig. 4. Analysis of the intramuscular nerve distribution in the first case. $*$ : distribution to the tendon. ?: unknown ends of nerves. 
fundum digitorum). The innervation in this case was unknown.

\section{Case 3.}

The muscle variation in the left forearm of a male cadaver was similar to that of the second case and Gantzer's muscle was also observable in this case (Fig. 6). The differences in shape between the two cases were as follows. The muscle variation in the third case

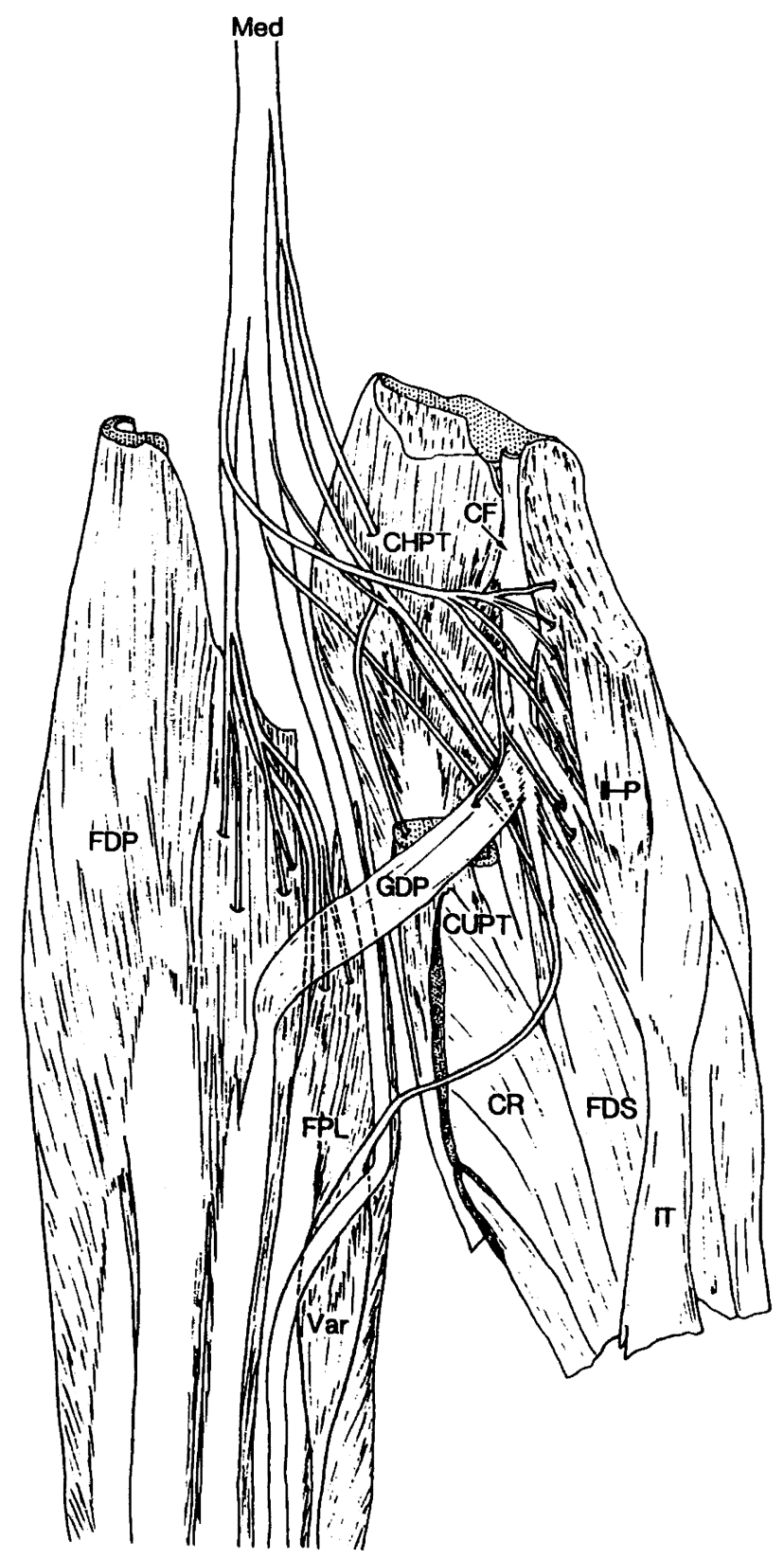

Fig. 6. Anterior view of the left forearm deep flexors and turned-out superficial flexors with the related nerves in the third case. arose tendinously from CF and its tendon of insertion partially spread on the deep surface of the flexor retinaculum after it was partially inserted into the proximal margin of the retinaculum. The innervation of this variation was also unknown.

\section{Discussion}

This kind of variation of muscle is very rare. As far as the present authors know, there in no description in any previous report in the literature (Frohse \& Fränkel, 1908; Le Double, 1897; Loth, 1931; Nishi, 1952; Testut, 1884).

The characteristics of this variation are that it arises from the well developed fascia (CF) and crosses the median nerve posteriorly to insert into the flexor retinaculum. In terms of the conservative morphology it is in some respects similar to variations of the palmaris longus (Takisawa et al., 1979), Gantzer's muscle (Gantzer, 1813) and the flexor carpi radialis brevis (Yoshida, 1978). The remarkable differences among them are in their position and course. The palmaris longus and the flexor carpi radialis brevis do not arise from the deep surface of the flexor digitorum superficialis and never pass behind the median nerve. The insertion of Gantzer's muscle is also different from the variation in question. However, this variation can be identified with Gantzer's muscle as far as the manner of origin is concerned, based on the descriptive study of the latter muscle by one of the authors (Kida, 1988). Gantzer's muscle as M. accessorius ad flexorem pollicis longum arose from the well developed fascia (CF) in all the cases examined in his study. The identity of the origin and situation of the variation with those of Gantzer's muscle may indicate a close relation between the two muscles.

Before comparing the related muscles according to innervation some clarification is required. Fürbringer's nerve-muscle specificity 
has been denied (Cunningham, 1882; Haines, 1936; Straus, 1946). Cunningham (1890), however in another sense, accepted the special relation between nerve and muscle, and Straus (1946) referred to some other studies, showing a certain specificity between them. The present authors also consider Cunningham's hypothesis to be very attractive. Therefore they developed the term "corrected" nervemuscle specificity, and are convinced that the concept of the branching pattern of the median nerve based on "corrected" specificity can give reliable results for the homogeny and phylogeny of muscles.

On the basis of "corrected" nerve-muscle specificity, from his findings obtained, Yamada (1986) concluded as follows. "The flexor digitorum superficials (FDS) does not totally derive from the deep forearm flexor (which covers the flexor digitorum profundus and the flexor pollicis longus), but only the proximal belly of FDS for the index finger (II-P) derives from the deep forearm flexor. The presence of Gantzer's muscle shows a close relation between II-P and FDS. The FDS without II-P comes from certain palmar muscles. Thus the forearm flexors are classified into three groups according to their innervation (Table 1)". Yamada's conclusion has been supported by the finding of one of the authors (Kida, 1988). Yamada (1986) presented a scheme of the common branching pattern of the median nerve (Fig. 3A). The schematic branching pattern in the authors' first case is very similar to the common pattern, and the twig to the variation in question comes from the nerve group to Yamada's original antebrachial flexor group (Fig. 3B). Since the muscle variation receives a nerve twig from the muscular branch to Yamada's original antebrachial flexor group, it is considered to have a close relation to Gantzer's muscle belonging to the same group.

Although the findings obtained are neither complete nor sufficient in number, the authors suggest that there should be no problem to recognize the variation of muscle as being much closer to, or the same as, Gantzer's muscle based on the results obtained by means of both conservative myology and nerve fiber analysis in the present study. As mentioned above, the muscle variation in question is inserted into the flexor retinaculum, while Gantzer's muscle is inserted either into the flexor digitorum pollicis longus or into the flexor digitorum profundus. The difference in the insertion between the two muscles does not seem to play an important role in the determination of muscle phylogeny made in this study. The origin and insertion of muscle is not essential to the muscle phylogeny, but seems to mainly depend on the muscle action

Table 1. Classification of forearm flexors according to their innervation (Yamada, 1986).

Antebrachial pronator

Original antebrachial flexor
PT(CH, CU), FCR

PL, II-P, [GPL/GDP]

[GPL/GDP], FPL/FDP, (PQ)

Migrated antebrachial flexor $-\square$ III $\cdot$ IV $\cdot$ V 
required. It should be remembered that changes in both origin and insertion of muscle among different animals, including man, can be frequently traced through the course of evolution.

For a long time it has been supposed that the flexor digitorum superficialis derives from the deep forearm flexor and the presence of Gantzer's muscle shows a close relation between the flexor digitorum superficialis and the deep forearm flexor (Howell, 1936; McMurrich, 1902; Romer, 1965; Starck, 1982; Straus, 1942). In support of Yamada's abovementioned hypothesis, however, the present authors propose a possible explanation that the variation in question inserted into the flexor retinaculum may show an original or archaic pattern from which the human palmaris longus, II-P and the deep forearm flexor have derived and transformed in the course of evolution, because Gantzer's muscle in man can be recognized as the muscle bundle formed in consequence of an incomplete separation of the deep forearm flexor from II-P, both of which muscles belong to Yamada's original antebrachial flexors and may be homologous to the palmaris communis (of McMurrich, 1902) inserted into the palmar aponeurosis in reptiles

\section{Acknowledgement}

The present authors are deeply indebted to Prof. Iwataro Morimoto, St. Marianna University School of Medicine, and Prof. Yukio Dodo, Sapporo Medical College, for the constant guidance in the course of this study. They express their thanks to Prof. Katsuzi Kumaki, Niigata University School of Medicine, for the permitance to use a material. They are also very grateful Assoc. Prof. J.P. Barron, St. Marianna University School of Medicine, for grammatical review of the manuscript.

\section{References}

1) Cunningham, D.J.: The relation of nerve-supply to muscle-homology. J. Anat. Physiol., 16: 1-9, 1882.

2) Cunningham, D.J.: The value of nerve-supply in the determination of muscular homologies and anomalies. J. Anat. Physiol., 25: 31-40, 1890.

3) Eisler, P.: Die Homologie der Extremitäten. Abhandl. Naturforsch. Gesellsch. Halle, XIX: 1-258, 1895.

4) Frohse, F. \& Fränkel, M.: Die Muskeln des menschlichen Armes. In v. Bardeleben's Handbuch der Anatomie des Menschen, Band II, Abt. II, Teil II: 101-151, Gustav Fischer, Jena, 1908.

5) Gantzer, C.F.L.: Dissertatio anatomica musculorum varietatis sistens. 13-14, Joannis Friderici, Berlin, 1813.

6) Gräfenberg, E.: Die Entwicklung der Knochen, Muskeln und Nerven der Hand und für die Bewegungen der Hand bestimmten Muskeln des Unterarms. Anat. Hefte, Abt. I, Band 30: 7-154, 1906.

7) Haines, R.W.: A consideration of the constancy of muscular nerve supply. J. Anat., 70: 33-55, 1936.

8) Haines, R.W.: The flexor muscles of the forearm and hand in lizards and mammals. J. Anat., 84: 13-29, 1950.

9) Howell, A.B.: Phylogeny of the distal musculature of the pectoral appendage. J. Morphol., 60: 287-315, 1936.

10) Kida, M.: The morphology of Gantzer's muscle, with special reference to the morphogenesis of the flexor digitorum superficialis. Acta Anat. Nippon., 63: 539-546, 1988. (in Japanese)

11) Le Double, A.F.: Traité des variations du systéme musculaire de l'homme. Tome II: 79-110, Schleicher, Paris, 1897.

12) Lewis, W.H.: The development of the arm in man. Am. J. Anat., 1: 145-183, 1902.

13) Loth, E.: Anthropologie des parties molles. 191-212, Masson, Paris, 1931.

14) McMurrich, J.P.: The phylogeny of the forearm flexors. Am. J. Anat., 2: 177-209, 1902.

15) Nishi, S.: Miologio de la japano. Gunma J. Med. Sc., 1: 173-182, 1952.

16) Ribbing, L.: Die muskeln und Nerven der Extremitäten. In: Bolk, L. et al. (eds), Handbuch der Vergleichenden Anatomie der Wirbeltiere, Band Y: 571-601, Urban \& Schwarzenberg, Berlin, 1938.

17) Romer, A.F.: The vertebrate body. 3rd ed, 208-213, W.S. Saunders, London, 1965. 
18) Starck, D.: Vergleichende Anatomie der Wirbeltiere. Band 3: 66-72, Springer, Heidelberg, 1982.

19) Straus, W.L., Jr.: The homologies of the forearm flexors: Urodeles, Lizards, Mammals. Am. J. Anat., 70: 281-316, 1942.

20) Straus, W.L., Jr.: The concept of nerve-muscle specificity. Biol. Revs., 21: 75-91, 1946.

21) Takisawa, A. et al.: A rare case of M. palmaris profundus. Acta Anat. Nippon., 54: 136-139,
1979. (in Japanese)

22) Testut, L.: Les anomalies musculaires chez l'homme. 430-509, G. Masson, Paris, 1884.

23) Yamada, T.K.: Re-evaluation of the flexor digitorum superficialis. Acta Anat. Nippon., 61: 283-298, 1986. (in Japanese)

24) Yoshida, Y.: On the flexor carpi radialis brevis muscle in man. Acta Anat. Nippon., 53: 323-324, 1978. (in Japanese)

\begin{abstract}
Abbreviations for all figures.
CF: connecting fascia. CHPT \& CUPT: humeral and ulnar heads of PT. CR: radial head of FDS. FCR: flexor carpi radialis. FCU: flexor carpi ulnaris. FDP: flexor digitorum profundus. FDS: flexor digitorum superficialis. FPL: flexor pollicis longus. GDP: M. accessorius ad flexorem profundum digitorum (Gantzer's muscle). GPL: M. accessorius ad flexorem pollicis longum (Gantzer's muscle). IT: intermediate tendon of FDS. M or Med: median nerve. MS: muscle spindle. N: nerve twig to supply the muscle of variation. PL: palmaris longus. PT: pronator teres. PQ: pronator quadratus. RS: radial intermuscular septum. TS: tendon spindle. $U$ or Uln: ulnar nerve. US: ulnar intermuscular septum. Var: muscle of variation. VP: Pacinian lamellated corpuscle. II-D \& II-P: the distal and proximal muscle bellies of FDS for the index finger, and finally III, IV and V: muscle bellies of FDS for the middle, ring and little figners.
\end{abstract}




\section{PLATE}




\section{Explanation of Figure}

\section{Plate I}

Diagram to show the left forearm flexors. The superficial forearm flexors are turned out and laid on the ulnar side of the flexor carpi ulnaris (FCU) after being detached from the forearm bones. The superficial surface of the proximal muscle belly of the flexor digitorum superficialis for the index finger (II-P) is visible, since the major portion of the flexor digitorum superficialis (FDS), which naturally covers II-P, is also turned out. The epineurium of only the median nerve has been ensheathed. The origin of the muscle variation (Var) from the connecting fascia is observable in the middle of the superficial forearm flexors.

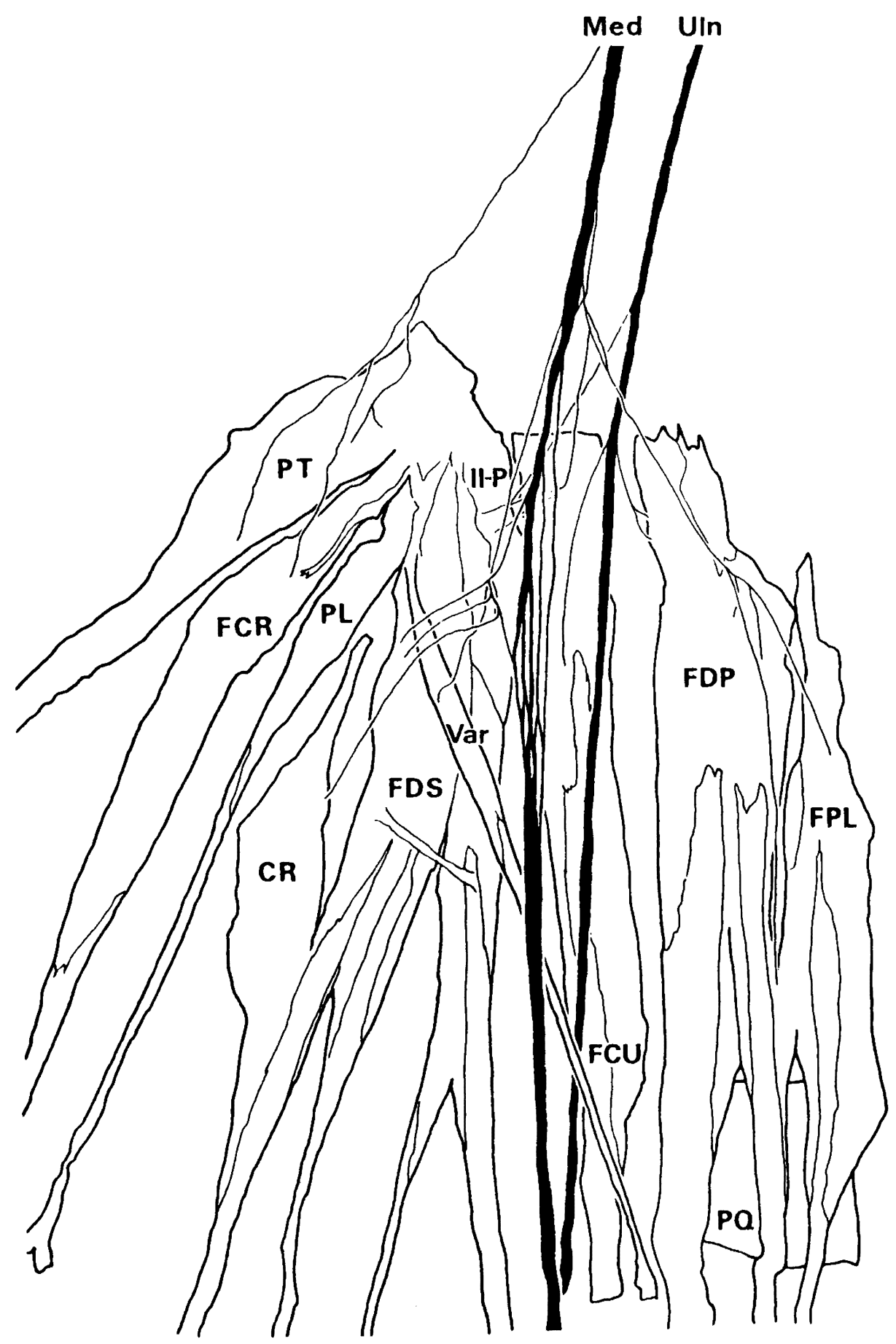


Plate I

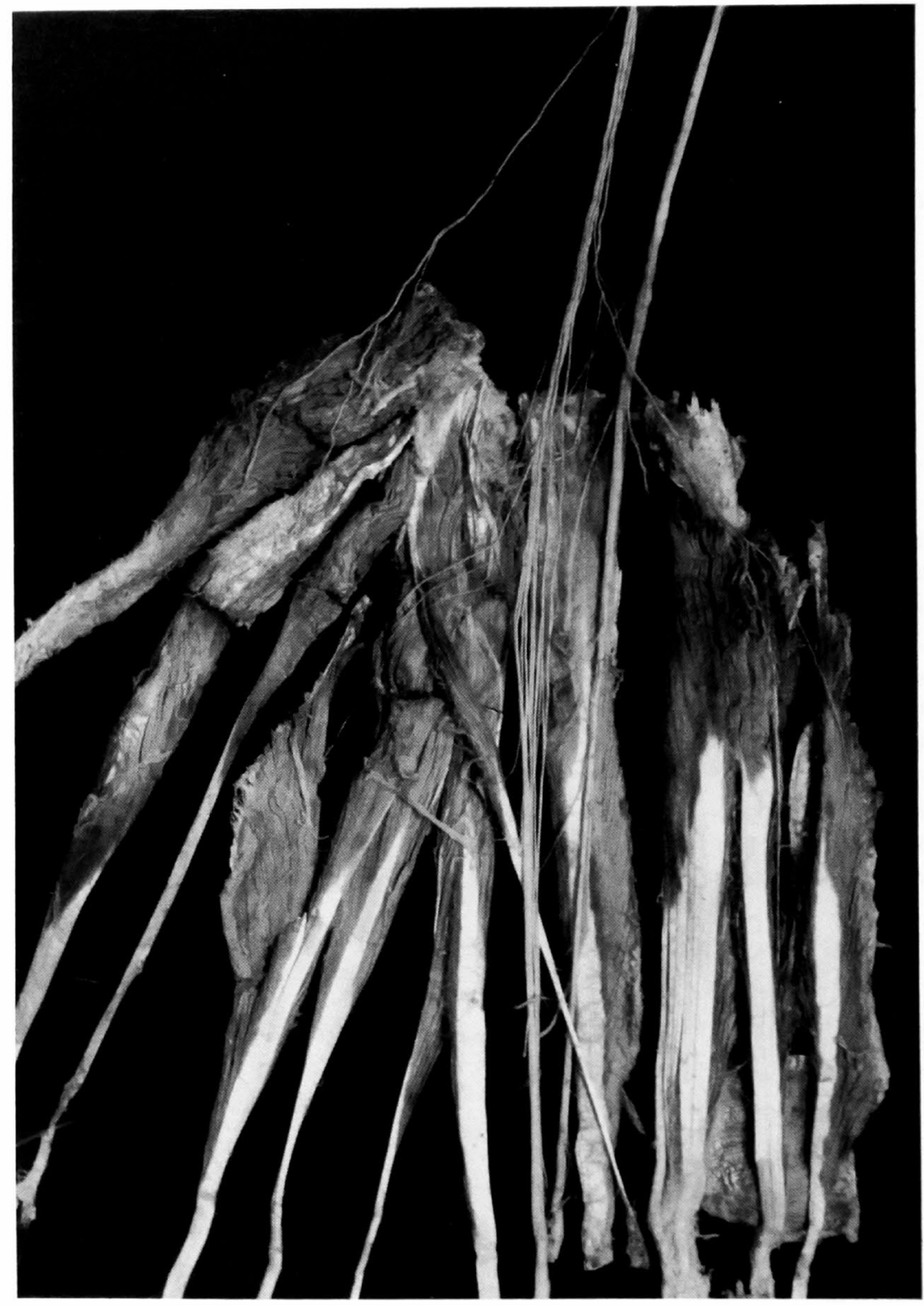

